\title{
Presepsin: A new marker of catheter related blood stream infections in pediatric patients(Letter)
}

- Javier, R.-M.Email Author,

- Diego, M.-M.,

- Jorge L, M.

- View Correspondence (jump link)

- Escuela de Medicina, Universidad Peruana de Ciencias Aplicadas, Peru

\section{Indexed keywords}

\author{
EMTREE \\ drug $\mathrm{C}$ reactive proteinpresepsinprocalcitoninproteinunclassified drug \\ terms: \\ abdominal discomfortarea under the curvebacteremiacatheter \\ EMTREE \\ medical \\ infectioncause of deathcell culture techniqueclinical evaluationclinical \\ terms: \\ featurecomparative studydiagnostic accuracydisease associationhospital \\ admissionhumanLetterleukocytemental diseasemental \\ healthpediatricspredictive valueprotein blood levelsensitivity and \\ specificitysuperinfectionsymptomtime to treatmentvomiting
}

\section{Chemicals and CAS Registry Numbers:}

C reactive protein, 9007-41-4; procalcitonin, 56645-65-9; protein, 67254-75-5

- ISSN: $1341321 \mathrm{X}$

- CODEN: JICHF

- Source Type: Journal

- Original language: English

- DOI: $10.1016 /$ j.jiac.2018.04.005

- Document Type: Letter

- Publisher: Elsevier B.V. 